\title{
Selos comemorativos brasileiros: uma proposta de representação do conhecimento
}

\author{
Kézia de Lira Feitosa ${ }^{I}$ \\ Diego Andres Salcedo ${ }^{\text {II }}$ \\ ${ }^{I}$ Universidade Federal de Pernambuco, Recife, PE, Brasil. \\ Mestrando no Programa de Pós-graduação em Ciência da Informação. \\ ${ }^{I I}$ Professor na graduação e no Programa de Pós-graduação em Ciência \\ da Informação. Coordenador do Grupo de Pesquisa Imago e Humanidades \\ Digitais.
}

http://dx.doi.org/10.1590/1981-5344/3592

Considera que a padronização técnica para a classificação e a indexação documentais interfere na qualidade do serviço de representação temática. Desenvolve, como objetivo principal, critérios e um modelo para representar tematicamente os selos postais comemorativos brasileiros. Justifica o estudo ao indicar melhor eficácia de acesso ao conjunto de informações contidas no selo postal. Caracterizou-se como uma pesquisa exploratória, bibliográfica e documental. Utilizou literatura científica das áreas da Biblioteconomia, da Ciência da Informação e da Filatelia. Identificou e recuperou essa literatura por meio da Base de Dados Referenciais de Artigos de Periódicos em Ciência da Informação (BRAPCI), da Scientific Electronic Library Online (SCIELO) e de livros produzidos por filatelistas. Fez uso, também, do blog dos Correios do Brasil, dos respectivos Editais de Emissão dos Selos Postais Comemorativos Brasileiros de 2017 e do Catálogo de Selos do Brasil de 2015. O resultado da pesquisa indica que os critérios de classificação e o modelo de indexação cumprem seu papel técnico de forma eficaz para a representação do selo postal comemorativo brasileiro. Conclui, também, que estudos futuros podem testar os critérios e o modelo em outros gêneros de selos postais. 
Palavras-chave: Biblioteconomia. Filatelia. Organização do conhecimento. Selo postal comemorativo.

\section{Brazilian commemorative stamps: a proposal to Knowledge representation}

It considers that the technical standardization for documentary classification and indexing interferes in the quality of the thematic representation service. It develops, as main objective, criteria and a model to thematically represent the Brazilian commemorative postage stamps. It justifies the study by indicating better effectiveness of access to the set of information contained in the postage stamp. It was characterized as an exploratory, bibliographical and documentary research. He has used scientific literature in the areas of Library Science, Information Science and Philately. He identified and recovered this literature through the Reference Database of Periodical Articles in Information Science (BRAPCI), Scientific Electronic Library Online (SciELO) and books produced by philatelists. He also made use of the blog of the Correios do Brasil, the respective Issuances of the Brazilian Postal Stamps of 2017 and the Brazilian Stamp Catalog of 2015. The results of the survey indicate that the classification criteria and the indexing model comply its technical role effectively for the representation of the Brazilian commemorative postage stamp. It also concludes that future studies can test the criteria and the model in other genres of postage stamps.

Keywords: Commemorative postage stamp. Librarianship. Knowledge Organization. Philately.

Recebido em 31.01.2019 Aceito em 13.02.2019

\section{Introdução}

A adoção de procedimentos e princípios para nortear o tratamento de um tipo documental específico é de fundamental importância para a padronização da representação do seu conteúdo. Existe um acentuado debate teórico e a contínua experimentação de procedimentos metodológicos, dos quais à área de representação temática, específica da Biblioteconomia, pode ser favorecida.

Ainda, é possível encontrar na literatura científica da Ciência da Informação certo debate sobre as metodologias utilizadas na 
representação temática dos documentos pictóricos, porém inexiste uma metodologia consolidada especificamente para a representação de selos postais do tipo comemorativo.

Com o intuito de preencher essa lacuna existente e tendo ciência de que a consistência, precisão, especificidade e relevância da informação constituem qualidades básicas no processo de busca e acesso à informação, quais seriam as etapas para elaboração, princípios e critérios a serem adotados durante o processo de representação temática de selos postais comemorativos?

Diante disso, o objetivo geral do estudo foi estabelecer os procedimentos para a representação temática de selos postais comemorativos brasileiros, por meio do estabelecimento de critérios e dos princípios de indexação, a partir da análise dos selos comemorativos emitidos pelos Correios do Brasil de 1900 até 2017.

O estudo e estabelecimento de diretrizes para a representação temática dos selos postais comemorativos não somente auxilia o profissional bibliotecário, enquanto técnica padronizadora dos serviços de classificação e indexação, como influencia diretamente na qualidade do serviço de representação deste singular documento, promovendo maior possibilidade de acesso ao conjunto de informações históricas, sociais, culturais e econômicas que estão contidas neles auxiliando colecionadores, pesquisadores e professores além de todo o público-alvo em potencial.

Sob uma perspectiva pedagógica, as informações extraídas dos documentos postais, como um todo, e em especial dos selos postais comemorativos, podem servir de subsídio para diversas abordagens e práticas didáticas.

A pesquisa analisa, ainda, o selo postal propriamente dito, um documento que demanda certa atenção do olhar e atitude ética, posto que nele jaz o potencial de perceber algumas transformações pelas quais passaram as pessoas e as instituições.

Sobre esses agentes, cabe ainda a percepção de que maneira foram conduzidos tanto o desenvolvimento tecnológico, quanto o progresso social e cultural, como, em alguma medida, reflete distanciamentos e aproximações, diferenças e semelhanças, como, de fato, são escolhidas as narrativas verbovisuais que contam uma visão histórica, dentre tantas silenciadas, ou, ainda, certa verdade sobre a natureza, enfim como as ideologias e os Estados ramificam os seus discursos.

Dito isso, em que pese o seu objetivo geral, a pesquisa foi do tipo exploratória (GIL, 2009) e, de acordo com os procedimentos, foi bibliográfica e documental. Utilizou literatura científica das áreas da Biblioteconomia, da Ciência da Informação e da Filatelia. Identificou e recuperou essa literatura por meio da Base de Dados Referenciais de Artigos de Periódicos em Ciência da Informação (BRAPCI), da Scientific Electronic Library Online (SciELO) e de livros produzidos por filatelistas. Fez uso, também, do blog dos Correios do Brasil, dos respectivos Editais de Emissão dos Selos Postais Comemorativos Brasileiros de 2017 e do Catálogo de Selos do Brasil de 2015. Exposto isso, a próxima seção 
realizou um debate teórico sobre a organização e representação do conhecimento.

\section{Organização do Conhecimento e a Representação Temática}

O conceito de Representação Temática está compreendido nas grandes áreas de Representação e Organização do Conhecimento. Existe certa divergência no uso e aplicação desses conceitos na Biblioteconomia e na Ciência da Informação (CI). Isso prejudica diretamente a eficiência e efetividade da comunicação científica e o quadro agrava-se ainda mais por tratar de conceitos centrais e essenciais da CI. Dessa forma, é salutar a discussão acerca desses conceitos.

Numa primeira visão, proposta por Brascher e Café (2008) no contexto da Organização e Representação da Informação, os registros informacionais são objeto de estudo e pesquisa, ou seja, o objeto é material e físico, diferentemente da Organização e Representação do Conhecimento que estão ligadas aos conceitos e ideias, ou seja, ligadas à abstração.

Seguindo essa linha de raciocínio, a Organização da Informação (OI) tem por objetivo possibilitar o acesso ao conjunto de conhecimento em potencial contido na informação. Contudo, segundo Svenonius (2000), para ser organizada, a informação precisa ser descrita e essa descrição pode ser entendida como um enunciado das propriedades de um objeto e suas relações com outros objetos.

Brascher e Café (2008) pontuam que ao pensar a descrição de conteúdo (elaboração de resumos, classificação e indexação) pode-se argumentar que os documentos em si não são representados, mas seus respectivos assuntos, pois como afirma Alvarenga (2006), os documentos não são classificados e sim os conceitos ali contidos. Consequentemente, esses dois processos implicam na Representação da Informação (RI), obtidos pelo processo de descrição física e de conteúdo e na Representação do Conhecimento (RC), uma estrutura conceitual para representar modelos.

Outra possibilidade interpretativa nesse debate teórico considera que as técnicas de organizar conhecimentos, se dentro do campo da Ciência da Informação, permite afirmar que aquela, para além de procedimentos técnicos, seria uma área de estudos própria com enfoque no ordenamento, na representação e na recuperação do conhecimento, este, por sua vez, organizado a partir de ações de profissionais de diversos e distintos saberes.

Nesse sentido, para Hjorland (2003) e Smiraglia (2002), autores internacionalmente reconhecidos pelas suas contribuições aos debates sobre a OC, fica claro que este ramo do saber versa sobre organizar informações em algum tipo de suporte ou, ainda, desenvolver ferramentas computacionais para recuperar, tratar e disseminar informações diversas e distintas ou entidades documentárias. 
Enquanto fundamentação teórica do trabalho ora em desenvolvimento, a definição de OC proposta por Anderson (1996, p. 337), parece salutar, a saber:

descrição de documentos, seu conteúdo, características e propósitos, e a organização destas descrições, para fazer destes documentos e de suas partes acessíveis às pessoas, buscando-os ou as mensagens que eles contém.

Pode-se concluir que a divergência referente à abrangência desses conceitos existe porque parte dos pesquisadores não compreende a prática descritiva documental enquanto organização de conhecimento, no sentido de que conhecimento é um conjunto de informações que foi processado e apreendido, sendo assim uma abstração.

Outros autores entendem que a OC envolve dois tipos distintos de organização, a cognitiva e a social. Feita a devida distinção dos conceitos de OI, RI, OC e RC, a partir da revisão bibliográfica, sigamos com a discussão acerca dos processos da Representação Temática.

\subsection{Classificação}

A classificação, além de uma teoria que circunda algumas das principais áreas de estudo da Ciência da Informação, também é um processo. Sob um olhar mais amplo, o ato de classificar é um fenômeno social que faz parte da vida humana há muito tempo. No decorrer das rotinas diárias nós atribuímos valores, juízos, títulos, nomenclaturas e estereótipos às pessoas e aos objetos.

Além de essas classificações serem feitas por indivíduos de certo grupo social ou comunidade, elas também são parte concreta da vida social, logo podem ser consideradas classificações sociais (COSTA, 1997/1998). Não apenas isso, para alguns autores, como Mai (2011) classificar é uma prática imanente humana e acontece por meio da linguagem sendo, assim, mais uma maneira de interagir socialmente.

Para além das "classificações sociais" são reconhecidas diversas maneiras de classificar o conhecimento produzido pelos humanos. Por exemplo, no período da Idade Moderna podemos observar um esforço maior na organização de forma sistemática do conhecimento humano. Burke (2003) revela que nesse momento histórico de transição aquele conhecimento era classificado por grupos diferentes de maneiras distintas. Essas classificações divergem entre duas abordagens distintas e complementares: a filosófica e a voltada para a organização e recuperação de documentos, denominada classificação bibliográfica.

Essa prática classificatória é mencionada, por exemplo, por Buckland (1991, p. 4), ao afirmar que

os seres humanos fazem coisas com a informação ou para a informação. Examinam, descrevem e categorizam. Compreendem, interpretam bem ou mal, resumem ou refutam. Podem até falsificála, alterá-la ou destruí-la. A essência da evidência é precisamente o 
que a percepção das pessoas pode alterar aquilo que acreditam que sabe.

Um dos papéis predominantes do profissional da informação é o de emissor-mediador entre a memória registrada pelas gerações passadas e a sociedade atual e futura. Fazer com que esse material esteja disponível em sua completude, por muito mais tempo, é de uma responsabilidade grande, visto que é por meio da memória humana, representada nos patrimônios históricos, que podemos ter acesso ao conhecimento produzido.

Nesse sentido, classificar tem valor social, seja coletivo seja individual. A classificação é uma ação humana útil para estipular o propósito e à aplicação dos objetos classificados. Assim, para todo ato classificatório, Ihe subjaz uma fundamentação, certas premissas basilares (BARROS; PADILHA, 2015).

Por sua vez, na área da Biblioteconomia, o conceito dado ao ato de classificar por Piedade (1977) mostra a essência desse processo, intrínseco às culturas humanas, à medida que separamos em partes um conjunto de objetos a partir das similaridades e distinções, considerando as qualidades e juízo de valor atribuídos pela própria sociedade e recorrentemente, pelo senso comum.

A classificação bibliográfica busca aperfeiçoar o acesso e recuperação aos documentos requeridos de forma a tornar o processo de busca mais eficaz e efetivo. A denominação de termos, que representam o conteúdo de um documento, funciona como remissiva que oferece pistas sobre o conteúdo no documento original, traços esses que podem possibilitar uma noção ampla ou com maior grau de especificidade.

Um dos impactos na Ciência da Informação acerca das concepções pós-modernas de classificação apontadas por Mai (2011) trata do significado dos signos. Considerado um documento enquanto signo, ou seja, a representação de algo a que atribuímos valor, significado ou sentido, o assunto não é extraído do documento, mas alcançado na mente de quem interpreta, seja o profissional ao executar o serviço de representação ou o usuário.

Essa perspectiva anula a ideia de um documento como um grupamento de informações a ser elucidado de forma precisa, o que remete a um importante posicionamento sobre o que significaria propor um processo de desclassificação, tema tratado a seguir.

\subsubsection{O processo de desclassificação}

O processo de classificar implica uma tarefa complexa que requer a disposição em classes de objetos e ideias que possuam características comuns. Esse processo pode ocultar e segregar saberes, na medida em que privilegia determinada cultura em detrimento da desvalorização de outras.

Dessa forma, considera-se o conceito de desclassificação, proposto por García Gutiérrez (2014), que contrapõe posicionamentos autoritários, 
burocráticos e conservadores dos profissionais da informação no ato de classificar e organizar o conhecimento. A desclassificação estaria assim voltada para uma reflexão crítica e em constante atualização que antecede o fazer da classificação e não tem o intuito de substituir esse processo.

Ainda, o autor pontua que se faz necessário o trabalho conjunto da construção de uma ética transcultural que apoie a construção social da exomemória, com o objetivo de evitar a prática classificatória de forma preconceituosa.

Exomemórias seriam as memórias exteriorizadas que passam despercebidas, abrangendo toda informação registrada - pensamentos, experiências, fotografias, revistas, multimídia - seja em suporte físico ou digital, conhecimentos ou lembranças (GARCÍA GUTIÉRREZ, 2006), sem privilegiar determinadas áreas ou discursos, incluindo os conhecimentos culturais, populares e artísticos.

Nesse sentido, Soares, Martin e Francelin (2013, p. 64) sugerem que

a construção da exomemória surge a partir dos preconceitos locais e globais com os conhecimentos que fogem da ordem préestabelecida. Por esse motivo é necessário o "desvelamento" dessas ideias pré-concebidas com o intuito de construir uma memória democrática e mista. Embora o conceito de exomemória esteja normalmente vinculado ao digital, não se limita a ele, pois, documentos de todos os tipos constituem a exomemória.

Essa noção de desclassificação recomenda a revisão constante dos processos complexos de tradução e sinaliza para o compromisso de ir além dos automatismos e preferências hierárquicas que a classificação condiciona. Este exercício possibilita um maior grau de contentamento do interagente, que pode ser medido através dos índices de especificidade, exaustividade, precisão e consistência, conceitos que serão tratados a seguir.

\subsection{Especificidade, exaustividade, precisão e consistência}

A exaustividade e especificidade estão relacionadas à identificação e seleção de conceitos durante a análise de assuntos de um documento. $\mathrm{Na}$ exaustividade, a seleção de termos impõe um número mais restrito de termos, porém o ideal seria que o documento estivesse representado por todos os seus assuntos, garantindo que a necessidade de recuperação do usuário fosse atingida.

Existe um debate teórico sobre esses conceitos na área de representação temática. Foskett (1973, p. 13) afirma que o conceito de exaustividade pode ser entendido como "a extensão com que analisamos um dado documento, a fim de estabelecer exatamente qual o conteúdo temático que temos de especificar".

Para que essa prática seja possível, Gil Leiva (1999, p. 26) indica que é necessária uma "seleção ou assinalação de todos os conceitos 
essenciais, explícitos ou implícitos no documento ou na pergunta documental". Trata-se da "abrangência do assunto coberto" (OLSON; BOLL, 2001, p. 91).

Em resumo, uma representação exaustiva implicaria então o emprego de termos suficientes para abranger o principal conteúdo temático do documento. "Quanto mais termos forem utilizados para indexar um documento, mais acessível ele se tornará e, provavelmente, mais vezes será recuperado", nas palavras de Lancaster (2004, p. 27).

Dois aspectos são essencialmente necessários para a compreensão desse conceito: a) $O$ aspecto quantitativo, no qual a exaustividade se refere ao número de termos atribuídos pelo indexador (LANCASTER, 2004); b) O aspecto de extensão da representação do conteúdo coberta pelos termos atribuídos pelo indexador (GIL LEIVA, 2008).

Em relação à especificidade, a seleção de termos poderá recair sobre termos mais genéricos e menos precisos, pois a preferência, em alguns casos, recai na escolha de um termo genérico, porém existem casos em que para aumentar a precisão escolhe-se um termo mais específico como é o caso de bibliotecas especializadas. Os conceitos de exaustividade, revocação e precisão estão diretamente relacionados.

Quanto mais exaustiva a indexação de documentos maior será a sua revocação, ou seja, o número de documentos recuperados na busca e, inversamente proporcional, a precisão será menor. A precisão neste estudo é entendida sob a perspectiva de Olson e Boll (2001, p. 88) enquanto "habilidade do catalogador de identificar quais conceitos representar e a habilidade do catalogador para traduzir estes conceitos em termos de um vocabulário controlado".

Para fins de recuperação de informação em sistemas, pode ser entendida ainda como "a extensão em que o sistema nos permite ser precisos ao especificarmos um documento que estejamos processando" (FOSKETT, 1973, p. 12), bem como a "capacidade do sistema em impedir a recuperação dos documentos não-relevantes" (CARNEIRO, 1985, p. 234). Para a recuperação ser precisa não basta ter muitos termos, mas é preciso que cada um desses termos tenha pertinência e relevância para o conteúdo temático que o documento aborda.

Outro aspecto diretamente ligado à qualidade do serviço de representação documental é a consistência da representação que "referese à extensão com que há concordância quanto aos termos a serem usados para indexar um documento" (LANCASTER, 2004, p. 68).

Em outras palavras, é necessário que os itens informacionais que tratam do mesmo assunto sejam avaliados desde uma abordagem conceitual o que, por sua vez, remete ao documento que interessa ao estudo em voga, o selo postal, tema da próxima seção.

\section{Os selos postais comemorativos brasileiros}

O selo postal surge na Europa durante o século XIX, no momento de manifestação dos Estados e transformações nas sociedades capitalistas do ocidente. Por volta de 1830, a Inglaterra já detinha um dos mais 
eficientes serviços postais já conhecidos. Algumas dessas transformações motivaram ou influenciaram a produção, a distribuição em massa e o consumo mundializado de selos postais, por sua vez sendo considerados documentos disseminadores em diversas áreas do saber (CASTRO et al., 2007).

Os detalhes desse sistema postal europeu são indicados no quadro a seguir:

Quadro 1: "Reforma postal" na Europa por volta de 1840

\begin{tabular}{|c|c|}
\hline O sistema postal europeu em 1840 & A "Reforma Postal" na Inglaterra \\
\hline $\begin{array}{c}\text { A tarifa poderia ser paga pelo remetente ou } \\
\text { destinatário da correspondência. }\end{array}$ & $\begin{array}{c}\text { Pagamento prévio da franquia conforme tarifas } \\
\text { pré-estabelecidas. }\end{array}$ \\
\hline $\begin{array}{c}\text { A tarifa compreendia: as medidas, o peso, a } \\
\text { classe e a distância a ser percorrida. }\end{array}$ & $\begin{array}{c}\text { Emissão de selos postais adesivos para } \\
\text { comprovar o pagamento das correspondências } \\
\text { conforme todo o seu projeto e circulação. }\end{array}$ \\
\hline $\begin{array}{c}\text { A arrecadação era difícil e a falta de pagamento } \\
\text { dos envios era alarmante. }\end{array}$ & $\begin{array}{c}\text { Tarifas uniformes dentro do país, considerando } \\
\text { o peso, mas sem levar em conta a distância, } \\
\text { com o intuito de diminuir custos e tornar o } \\
\text { serviço acessível para muitos. }\end{array}$ \\
\hline $\begin{array}{c}\text { O envio para regiões distantes somava as } \\
\text { dificuldades da própria distância e os meios } \\
\text { empregados, às cobranças relativas a cada } \\
\text { correspondência. }\end{array}$ & $\begin{array}{c}\text { Diminuição efetiva do valor das tarifas (1 penny) } \\
\text { a cada 14 gramas de correspondência enviada. }\end{array}$ \\
\hline
\end{tabular}

Fonte: Salcedo (2010, p. 78)

No contexto de produção dos primeiros selos postais é consensual a percepção de que a efígie, o brasão e a cifra foram os principais elementos pictóricos. Por sua vez, os elementos verbais mais utilizados foram, nos seus respectivos códigos linguísticos, o termo 'postal', o nome da soberana ou conquistador e, por fim, o nome da moeda corrente, também, na língua de origem do seu país emissor.

Posteriormente, alguns outros elementos foram sendo incorporados, à medida que as pessoas entenderam as suas várias funcionalidades. Neste momento, inicia-se a filatelia, ou seja, o colecionismo de selos postais. Após o surgimento e expansão de sua utilização para além da Europa, o selo postal enfim chega ao Brasil. Nesse sentido, são possíveis diversas e distintas leituras dos fatores tanto político-econômicos, quanto sócio-culturais, sobre as causas prováveis que culminaram com a emissão do selo postal adesivo no Brasil.

Indubitável é o fato de que a vinda da família real portuguesa para o Brasil contribuiu para que ocorresse uma ampla reforma no sistema de correios do Brasil. Além disso, o desenvolvimento do comércio, a estruturação das comunicações terrestres e marítimas e à abertura dos portos foram condições favoráveis para que houvesse essa reforma.

Um ano após o lançamento do primeiro selo postal adesivo, na Inglaterra, em 1840, tem início o Segundo Reinado, no Brasil, coroando D. Pedro II, em 17 de julho de 1841. Nesse novo cenário político-administrativo e depois de agitados anos do período regencial, o novo regente aprova, em 29 de novembro de 1842, dois Decretos - $\mathrm{n}^{\circ} 254, \mathrm{n}^{\circ} 255$ - que instituíram o uso do selo postal adesivo nas correspondências brasileiras (SALCEDO, 2010, p. 88). 
Assim, em 1 de agosto de 1843 os Correios do Império colocaram em circulação os 3 primeiros selos postais brasileiros, chamados de "Olhos-de-Boi" (ver figura 1).

Figura 1: Olhos-de-Boi de 30,60 e 90 Réis

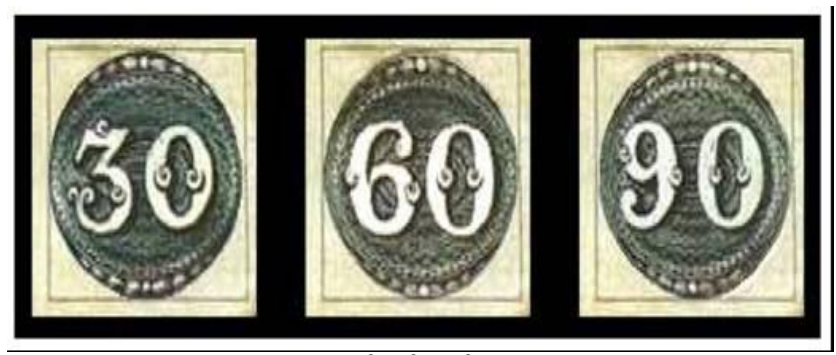

Fonte: propriedade dos autores

Confere a ideia sugerida por Penereiro e Cabrini (2013), ao considerarem que a Filatelia, no Brasil, em meados do século XIX, pode ser denominado um saber, certa prática social, que permitiu a produção de centenas de milhares de documentos filatélicos dotados de alta qualidade e criatividade.

Desde que começou a ser utilizado no país, o selo postal tornou-se uma atividade permeada por entusiasmo, ansiedade e paixão. De início, essa atividade era baseada apenas no agrupamento de correspondências, uma fase inicial de acumulação desorganizada das missivas, dos carimbos e, por fim, dos selos postais. Porém, em poucos anos de implementação dessa nova prática social no Brasil, efetivaram-se sistemas elaborados de emissão, circulação e uso desses documentos.

\subsection{Características verbo-visuais}

O estudo do conceito de documento tratado nas áreas de Documentação, Biblioteconomia e Ciência da Informação permite observar que o uso do conceito é usado tanto de forma especializada quanto de forma generalista, de forma a delimitá-lo, por vezes, à alguma fonte de informação física, ou não, em um meio específico.

Assim, considerada a possibilidade de estudo de documentos filatélicos nas áreas de conhecimento supracitadas, um selo postal pode ser considerado um documento, quando olhado atentamente por um historiador e que, para manter a memória social, dialoga com outros textos. Dessa forma, sua representação pode ser pensada enquanto representação de imagem em sua totalidade, o plano de expressão, a interface e a superfície material do selo postal.

Nesse sentido, para o campo da semiótica, toda linguagem possui dois planos dos quais resultam o sentido: o plano de expressão e o plano de conteúdo. O sentido, sob esta perspectiva, caracteriza-se segundo Pietroforte (2004, p. 12-13), por uma "rede de relações", o que quer dizer que os elementos do conteúdo só adquirem sentido por meio das relações estabelecidas entre eles. 
Por sua vez, Floch (2001, p.9) conceitua o plano de expressão enquanto "terreno onde as qualidades sensíveis que possui uma linguagem para se manifestar são selecionadas e articuladas por variações diferenciais". Entende-se que é tudo aquilo perceptível ao olhar, a veiculação do conteúdo.

Trata-se da materialidade do texto, um recorte de elementos de uma determinada linguagem que serão organizados para significar um conjunto de ideias e é no plano de conteúdo que as significações nascem de acordo com as ordenações e encadeamentos sob a visão de cada cultura.

É pertinente levar em consideração o conceito de "distância semiótica", apontado por Mai (2011, p. 721). Seria a observação da distância entre o objeto classificado e o sujeito que o classifica. Trata-se da constatação do caráter interpretativo e subjetivo da mente humana, de modo que qualquer que seja o esforço de classificar é desafiador e pode ser artificial.

Existe um acentuado debate teórico e a contínua experimentação de procedimentos metodológicos, dos quais à área de representação temática, específica da Biblioteconomia, pode ser favorecida. Ainda, é possível encontrar na literatura científica da Ciência da Informação certo debate sobre as metodologias utilizadas na representação temática dos documentos pictóricos.

O Quadro 2, a seguir, indica algumas tendências metodológicas de análise imagético-textual utilizadas desde o século $X X$.

Quadro 2: Autores e aparatos teórico-metodológicos para análise de imagens

\begin{tabular}{|c|c|}
\hline Autorles & Metodologias \\
\hline Panofsky (1939) & $\begin{array}{l}\text { Método Iconológico: descrição pré-iconográfica, } \\
\text { análise iconográfica e iconologia. }\end{array}$ \\
\hline Eco (1968) & $\begin{array}{c}\text { Sistema de códigos visuais: verbal e visual } \\
\text { (icônico) }\end{array}$ \\
\hline Barthes (1970) & $\begin{array}{l}\text { Abordagem Semiológica: denotação, conotação, } \\
\text { ancoragem, revezamento. Retórica da Imagem. }\end{array}$ \\
\hline Floch (1981) & Semiótica Estrutural. Teoria Gerativa de Sentido. \\
\hline Joly (1994) & $\begin{array}{l}\text { Descrição da Imagem. Reprodução do Texto. } \\
\text { Separaçăo e Análise da Imagem (plástica, icônica } \\
\text { e linguística) }\end{array}$ \\
\hline Prosser (1998) & $\begin{array}{l}\text { Antropologia e Sociologia Visual. Etnografia. } \\
\text { Evidência fotográfica. } \\
\text { Iconografia e Iconologia, Mitologias. } \\
\text { Análise de gênero e técnica, forma, estilo e } \\
\text { semiótica. Estruturalismo, reconstrução, contexto } \\
\text { físico. Hermnêutica. }\end{array}$ \\
\hline Emmison e Smith (2000) & $\begin{array}{l}\text { Análise de Evidência em duas dimensões: } \\
\text { quantitativa e qualitativa }\end{array}$ \\
\hline Leeuwen e Jewitt (2001) & $\begin{array}{l}\text { Análise do conteúdo. Estudos Culturais. Semiótica. } \\
\text { Iconografia. Perspectiva terapêutica. } \\
\text { Sociosemiótica. Etnometodologias. }\end{array}$ \\
\hline Rose (2001) & $\begin{array}{l}\text { Interpretação Compositiva. Análise de Conteúdo. } \\
\text { Semiologia, Psicanálise, Análise do Discurso. }\end{array}$ \\
\hline Emery (2002) & $\begin{array}{c}\text { Abordagem de } 7 \text { marcos interpretativos: formalista, } \\
\text { desconstrucionista, gênero, cultural, semiótico, } \\
\text { psicanalítico e social realista. }\end{array}$ \\
\hline Walker e Champlin (2002) & $\begin{array}{l}\text { Forma e conteúdo. Análise do Conteúdo. } \\
\text { Iconografia e Iconologia, Mitologias. } \\
\text { Análise de gênero e técnica, forma, estilo e } \\
\text { semiótica. Estruturalismo, reconstrução, contexto } \\
\text { fisico. Hermenêutica. }\end{array}$ \\
\hline
\end{tabular}

Fonte: Salcedo (2010, p. 155)

No sentido de atualizar o conteúdo do Quadro 2 e aproximar o debate ao campo da Ciência da Informação, alguns textos e seus respectivos autores fornecem detalhes positivos em relação às análises de 
documentos imagético-textuais, fundamentais ao processo de representação, a saber: Boccato e Fujita (2006); Maimone e Gracioso (2007) e Sousa, Fujita e Gracioso (2014), dentre outros.

Por fim, analisar textos documentos imagético-textuais alude à tradução verbal e interpretação do aspecto visual do documento, como fotografias, selos postais, pinturas, etc. Há um trabalho de significação dos conteúdos implícitos e explícitos. Desse conjunto de documentos, o selo postal do tipo comemorativo, tem características verbovisuais que transcendem a função administrativo-postal e por isso interpelam, para além das esferas do mercado filatélico, todos que com ele se deparam.

Exposta essa breve história do selo postal, do colecionismo filatélico e do advento do tipo de selo comemorativo, a seção a seguir explanará sobre a proposta de análise do selo.

\section{Análise dos selos comemorativos}

Diferentemente de outros tipos de selos postais, os comemorativos têm sua tiragem e seu período de validade e circulação pré-determinados pelos Atos Normativos e Editais. Por convenção, três elementos verbovisuais devem constar impressos conforme um padrão normativo internacional: motivo da emissão, valor facial e nome do país ou da instituição emissora.

Os elementos contidos neste tipo de documento modificaram-se progressivamente. Sob uma perspectiva didática, pode-se separar essas mudanças em dois momentos: um primeiro momento em que predominam as representações de grandes personalidades, geralmente ligadas ao sistema político, assim como certa alusão a alguns eventos específicos e um segundo momento em que começam a surgir as recorrências temáticas na representação, como por exemplo os esportes individuais, fauna e flora.

Esses elementos verbovisuais constituem o plano de expressão, a interface, a superfície material de um selo postal. Ao ser analisado sob esse enfoque, o documento estará sendo interpretado com base nos assuntos que estão ali representados, caracterizando, assim, o seu tratamento informacional e documental.

Essa abordagem considera as suas estruturas significantes, que por sua vez possibilita construção de sentidos, além de supor processos de decodificação e interpretação. Na fase de decodificação dos elementos do objeto estudado é importante ter noção das delimitações da sua macroestrutura.

No caso do selo postal comemorativo, a macroestrutura alcança obrigatoriamente o motivo da emissão, o valor facial e o nome do país ou entidade emissora, além da gravura e termos que funcionam como legenda da história que pretende-se representar e divulgar através do selo postal comemorativo.

Parte desse processo remete à leitura de seus códigos icônicos. Surge o significado ao leitor a partir da interpretação dos conteúdos, do contato com a interface imagética, e da disposição técnica do suporte. Por 
fim, expostos alguns importantes referenciais teóricos que norteiam a pesquisa em andamento, a seguir são apontados os procedimentos metodológicos utilizados.

\subsection{Critérios e protótipo de representação}

Ao considerar que "objetos não são ordinariamente documentos mas se transformam em, se processados com finalidades de fornecer informação" (BUCKLAND, 1991, p.7), torna-se o selo postal objeto de estudo da Ciência da Informação como fonte a ser analisada e disponibilizada como qualquer outro documento.

Manini (2002) propõe um esquema para representar o conteúdo informacional de imagens em distintas categorias informacionais:

Quadro 3: Esquema de indexação de imagens

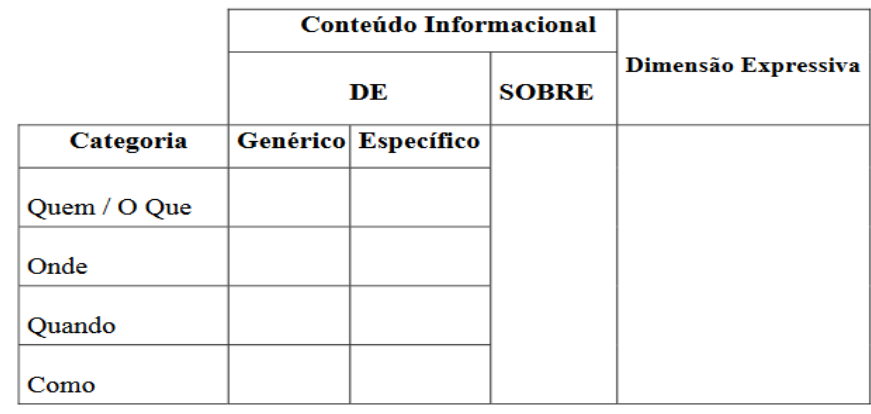

Fonte: adaptado por Manini (2002)

Este esquema tem o objetivo de sistematizar as informações contidas no documento visual, a fim de levantar termos descritores que se baseiam tanto na imagem, quanto das inferências de quem o descreve, a partir de conhecimentos prévios.

O fato é que mesmo com a existência de instrumentos facilitadores, produzidos e estudados na Ciência da Informação, a extração de todo conteúdo de um documento imagético, especificamente o selo postal comemorativo, ainda é um desafio, como bem pontua Mai (2011).

A partir do debate gerado e revisão constante dos resultados alcançados em um primeiro momento de pesquisa, considerando os métodos e ferramentas já citados e o tipo documental em questão foram estabelecidos sete critérios e um método para a representação de selos postais comemorativos (ver quadro 4) propostos e esquematizados a seguir:

1) O primeiro critério diz respeito à transcrição do conteúdo verbal do selo postal. Estabelece que o enunciado verbal, ou legenda, deve ser reproduzido em seu formato ortográfico original, independentemente do acordo ortográfico da língua portuguesa em vigência.

2) O segundo critério indica que o ano de emissão do selo, não seja interpretado como legenda. A confusão pode ocorrer 
por conta da organização das informações no suporte. É comum que neste tipo de selo apareçam o ano de emissão do selo e o ano de acontecimento do evento comemorado. Em alguns casos, o ano de emissão pode estar diretamente relacionado com o tema de celebração. Por isso é pertinente considerá-lo na representação temática. Dessa forma, o ano de acontecimento do evento deve ser indicado junto ao descritor 'evento' e a data de emissão em 'ano de emissão'.

3) O terceiro critério diz respeito à descrição do ano de emissão do selo. Percebe-se que alguns selos comemorativos não possuem em sua impressão o ano de emissão. Neste caso, essa informação deve ser retirada do Catálogo de Selos do Brasil (MEYER, 2015) ou do Edital de Emissão publicado pelos Correios. Considere que todo ano é publicado um novo catálogo, atualizando seu conteúdo com as novas emissões anuais dos Correios do Brasil.

4) É comum que um selo comemorativo seja emitido em virtude de um evento ocorrido, mas apareça a figura de uma pessoa ou instituição. Neste caso, o quarto critério estabelece que a pessoa ou instituição devem ser indicados, em 'indivíduo' ou 'instituição'.

5) Quando um selo fizer parte de uma série impressa, é indicado que essa informação esteja clara, por tratar-se de uma informação essencial aos pesquisadores e colecionadores.

6) O sexto critério indica que, a descrição deve detalhar as características da ilustração, tendo cautela para que a descrição feita não seja generalista e tampouco superficial.

7) Por último, os documentos serão nomeados de acordo com o título atribuído pelo Catálogo de Selos do Brasil (MEYER, 2015) ou pelo Edital de Submissão dos correios.

Exposto isso, considerar-se-á os critérios articulados com os descritores do quadro 3 , em que são indicados os campos que serão explicados a seguir:

a) Imagem-motivo: o conjunto de elementos pictóricos na interface documental que diz respeito ao motivo de emissão do selo postal.

b) Indivíduo: Personagens relacionadas ao motivo de emissão que estejam representados no documento.

c) Evento: Acontecimentos relacionados ao motivo de emissão do documento e que estejam representados no selo postal. 
d) Instituição: Entidades e/ou organizações relacionadas ao motivo de emissão e que estejam representadas no documento.

e) Legenda: Elementos verbovisuais textuais que podem ou não aparecer na interface.

f) Ano de emissão: Ano de emissão do selo postal comemorativo que pode estar, ou não, diretamente relacionado com o tema de celebração.

Quadro 4: Segundo protótipo de modelo para representar selos postais

\begin{tabular}{|c|c|}
\hline MMAGEM-MOTIVO & \\
\hline INIVIDUO & \\
\hline EVENTO & \\
\hline INSTITUÇAं0 & \\
\hline LEGENDA & \\
\hline ANO DE EMISSAO & \\
\hline
\end{tabular}

Fonte: produção dos autores a partir de dados de pesquisa

Então, sabendo-se que existe um padrão normativo internacional de elementos constituintes dos selos comemorativos, adotados pelo Brasil desde 1900, estes critérios e o protótipo de representação podem ser aplicados a todos os selos postais comemorativos brasileiros emitidos de 1900 até os dias atuais. Mas, vale pontuar que eles seriam o mínimo necessário, pois outros campos poderão ser demandados a partir de outras classificações.

Considerando que a documentação filatélica brasileira é dividida em várias dezenas de tipos distintos de documentos, será comentada, num primeiro momento, a classificação do sétimo selo postal do tipo comemorativo emitido pelos Correios no ano de 2017. Nesta pesquisa, o contato com o objeto de estudo foi feito por meio da Programação Filatélica 2017 dos Correios do Brasil, disponível no site oficial dos Correios.

Nesta fonte, foi possível acessar o próprio documento, bem como o Edital de Emissão Comemorativa $N^{\circ} 07$ (2017), possibilitando 0 enriquecimento das informações existentes no próprio documento, de forma que seja feito o uso adequado dos termos descritores com um olhar atento ao grau de precisão na representação desse documento.

Diante disso foi pensada a importância que deve ser dada aos termos descritores do selo postal comemorativo levando em consideração a sua natureza e elementos intrínsecos a este documento, que por sua vez exigem maior grau de exaustividade, que (LANCASTER, 2004, p. 27) conceitua como 
o emprego de termos em número suficiente para abranger o conteúdo temático principal do documento, ou seja, conseguir o maior número de termos indexadores para compreender a temática primeira do documento.

Quanto mais termos forem utilizados para indexar um documento, mais acessível ele se tornará e, provavelmente, mais vezes será recuperado. O selo postal comemorativo deve ser analisado em sua totalidade no processo de representação temática.

Dito isso, na Figura 2, a seguir, tem-se os descritores que podem ser considerados na análise desse tipo de documento.

Figura 2: Componentes de análise do selo postal comemorativo

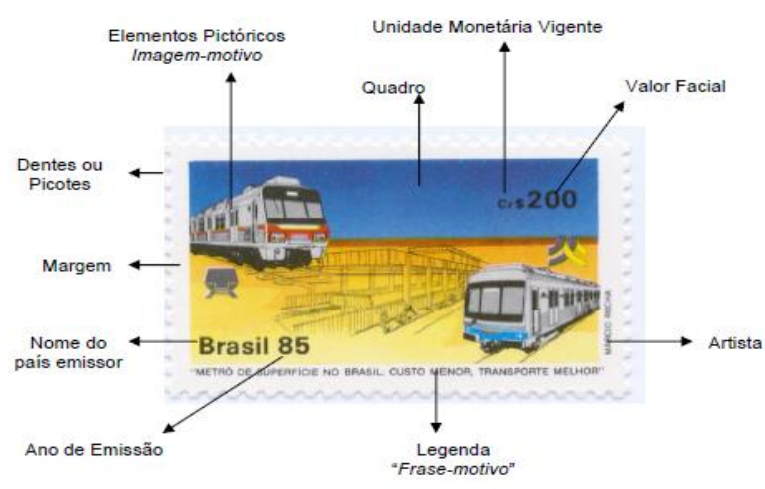

Fonte: Salcedo (2010, p. 153)

Diante da exposição dos elementos que podem ser levados em consideração ao analisar o selo postal comemorativo, bem como o que já foi exposto a respeito do método de classificação elaborado e utilizado, avancemos para o enfoque prático da pesquisa. Por conta da extensão do material classificado foi selecionado o sétimo selo comemorativo emitido no Brasil, em 2017 (ver figura 3), a partir do Edital de Emissão Comemorativa dos Correios n 07/2017.

\subsubsection{Aplicação do protótipo}

O documento representado nesta pesquisa é o sétimo selo emitido no Brasil no ano de 2017, em virtude da comemoração do Bicentenário da Revolução Pernambucana de 1817.

Figura 3: Bicentenário da Revolução Pernambucana

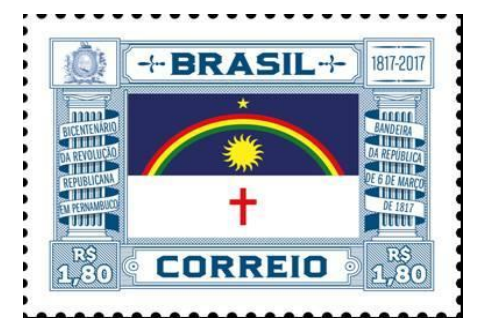


Fonte: Correios (2017)

\begin{tabular}{|c|l|}
\hline IMAGEM-MOTIVO & $\begin{array}{l}\text { Representação da Bandeira de Pernambuco nas } \\
\text { cores originais entre duas colunas jônicas que } \\
\text { sustentam o nome BRASIL. No canto superior } \\
\text { esquerdo encontra-se o brasão pernambucano. No } \\
\text { canto superior direito o ano de acontecimento da } \\
\text { Revolução Pernambucana (1817) e seu } \\
\text { bicentenário (2017). }\end{array}$ \\
\hline INDIVIDUO & Não aplicado. \\
\hline EVENTO & Revolução pernambucana de 1817 \\
\hline INSTITUÇAO & Estado de Pernambuco \\
\hline LEGENDA & $\begin{array}{l}\text { Bicentenário da Revolução Republicana em } \\
\text { Pernambuco. Bandeira da república de } 6 \text { de março } \\
\text { de } 1817 .\end{array}$ \\
\hline ANO DE EMISSAO & 2017 \\
\hline
\end{tabular}

O selo aborda em destaque a bandeira de Pernambuco criada em 1817, mas que só foi oficializada no seu centenário, em 1917, pelo então presidente da província Manuel Antônio Pereira Borda. Trata-se de uma releitura do selo do Centenário, de 1917 (ver figura 4). Alguns elementos foram atualizados, como a ortografia, a moeda vigente e as datas.

Também foi retificado o motivo de emissão. Passados 100 anos desde sua primeira versão, agora, comemora-se o Bicentenário. Outra remodelagem é a inserção das cores originais da bandeira pernambucana: amarelo, azul escuro, branco, verde e vermelho, enquanto no selo comemorativo emitido em 1917, sua tonalidade era toda azul.

Figura 4: Selo do Centenário de 1817

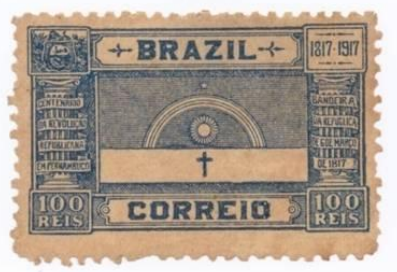

Fonte: propriedade dos autores (2017)

O grau de especificidade da representação documental irá depender do quão exaustivo será o trabalho do indexador. Os documentos variam de acordo com a sua tipologia, entre eles existem os documentos nãográficos que englobam os audiovisuais, os pictóricos e os sonoros. No caso que interessa ao estudo, os selo postal enquadra-se na qualidade de documento verbo-visual, que pode ser entendido e utilizado, para a finalidade aqui proposta, como sinônimo de pictórico.

Pode-se experimentar neste estudo o quanto os graus de especificidade e exaustividade da representação temática alteram-se de acordo com cada imagem a ser analisada, para além de todas as especificidades comuns aos selos postais comemorativos. Importante salientar que a pesquisa em outras fontes para além do documento a ser analisado, bem como a compreensão do assunto tratado por parte de quem classifica, incluindo os conhecimentos inerentes à pessoa, são indispensáveis para o enriquecimento deste serviço. 


\section{Considerações finais}

Ao considerar a trajetória percorrida até aqui baseada tanto na pergunta sobre quais seriam as etapas da representação temática de selos postais comemorativos (elaboração, princípios e critérios), quanto no objetivo geral do estudo, o qual foi estabelecer os procedimentos para a representação temática de selos postais comemorativos brasileiros, por meio de critérios e dos princípios de indexação, pode-se afirmar que o objetivo da proposta foi alcançado.

O debate gerado desde a construção dos critérios, bem como da ferramenta metodológica elaborada para a representação do objeto de pesquisa e a sua aplicação atenderam ao propósito da pesquisa e funcionaram de forma eficaz e efetiva enquanto instrumento técnico para representação temática de selos postais comemorativos.

Ficou claro durante a revisão bibliográfica que apesar dos novos conceitos sugeridos por García Gutiérrez indicarem a possibilidade de recriar outras práticas de classificação, é, também, salutar entender que uma mudança radical causaria um choque insalubre na estrutura dos conhecimentos atualmente, organizados e disponibilizados.

Mesmo assim, vale pontuar que o selo postal comemorativo brasileiro está sendo utilizado como item informacional para testar novas formas de organização e representação na WEB, no projeto de desenvolvimento do Repositório Filatélico Brasileiro (REFIBRA), devidamente homologado pelas respectivas instâncias da Universidade Federal de Pernambuco (UFPE), bem como cadastrado no grupo de pesquisa do Conselho Nacional de Desenvolvimento Científico e Tecnológico (CNPq) sob a nomenclatura "IMAGO: filosofia, ética, ciência, tecnologia, colecionismo e memória", articula atividades de pesquisa, ensino, extensão e cultura coordenadas pelo Grupo de CoPesquisa IMAGO em parceria com o Departamento de Ciência da Informação (DCI), da UFPE, desde 2014.

Foi feito o tratamento temático do documento postal diante da perspectiva adotada, tendo em vista que a partir das especificidades encontradas diante da análise documental, o método aplicado é mutável e recorrentemente discutível, tendo o mesmo passado por algumas adaptações e modificações.

Cabe ainda indicar que o trabalho contribui com a difusão livre da memória e da identidade nacional. A disponibilização desse tipo de patrimônio documental significa criar a chance para que a população preserve e também renove o olhar sobre a sua própria identidade.

\section{Referências}

ALVARENGA, L. Representação do conhecimento na perspectiva da Ciência da Informação em tempo e espaço digitais. R. Eletr. Bibliotecon. Ci. Inf., Florianópolis, v. 8, n. 15, p.18-40, 1.sem. 2006. 
ANDERSON, J. D. Organization of knowledge. In: FEATHER, J.; STURGES, P. (Ed.). International Encyclopedia of Information and Library Science. London: Routledge, 1996. p. 336-353.

BARROS, C. M.; PADILHA, R. Novas perspectivas para a classificação. Em Questão, v. 21, n. 1, 2015. Disponível em: http://www.brapci.ufpr.br/brapci/v/a/17150. Acesso em: 02 Set. 2017.

BOCCATO, V. R. C.; FUJITA, M. S. L. Discutindo a análise documental de fotografias: uma síntese bibliográfica. Lisboa, Cadernos BAD, v. 2. n. 1, p. 84-100, 2006.

BRASCHER, M.; CAFÉ, L. Organização da informação ou organização do conhecimento? In: ENCONTRO NACIONAL DE PESQUISA EM CIÊNCIA DA INFORMAÇÃO, 9, 2008, São Paulo. [Anais...]. São Paulo: USP, 2008.

BUCKLAND, M. K. Information as thing. Journal of the American Society for Information Science (JASIS) , v. 45, n. 5, p. 351-360, 1991.

CARNEIRO, M. V. Diretrizes para uma política de indexação. Revista da escola de Biblioteconomia da UFMG, Belo Horizonte, v. 14, n. 2, p. 221241, set. 1985.

CASTRO, J. F. M.; DINIZ, A. M. A.; BARROS, G. F. Interseções Geográficas: uma análise da cartografia filatélica brasileira. Sociedade \& Natureza, Uberlândia, v. 19, n. 2, p. 153-169, 2007.

CORREIOS. Edital de Emissão Comemorativa n 7. 2017. Disponível em: https://goo.gl/z7ZhuK Acesso em: 02 set. 2017.

FLOCH, J. Alguns fundamentais em Semiótica Geral. Documentos de estudo do Centro de Pesquisas Sociossemióticas, 2001.

FOSKETT, A. C. A abordagem temática da informação. São Paulo: Polígono; Brasília: UnB, 1973.

GARCÍA GUTIÉRREZ, Antonio. Cientificamente favelados: uma visão crítica do conhecimento a partir da epistemografia. Transinformação, Campinas, v.18, n.2, p.103-112, maio/ago. 2006.

GARCIA GUTIERREZ, A. Epistemología de La documentación. Barcelona: Stonberg Editorial, 2014.

GIL, A. C. Como elaborar projetos de pesquisa. 4. ed. São Paulo: Atlas, 2009.

GIL LEIVA, I. La automatización de la indización de documentos. Gijón: Trea, 1999.

GIL LEIVA, I. et al. Consistência na Indexação em bibliotecas universitárias brasileiras. TransInformação, Campinas, v.20. n.3, p.23353, set./dez. 2008.

HJORLAND, B. Fundamentals of knowledge organization. Knowledge Organization, Wurzburg, v. 30, n.2, p. 87-111, 2003. 
LANCASTER, L. W. Indexação e resumos: teoria e prática. 2. ed. Brasília [DF]: Briquet de Lemos, 2004.

MAI, J. E. The modernity of classification. Journal of Documentation, London, v. 67, n. 4, p. 710-730, 2011

MAIMONE, G. D.; GRACIOSO, L. de S. Representação temática de imagens: perspectivas metodológicas.. Informação \& Informação, Londrina, v. 12, n. 1, p. 130-141, jul. 2007.

MANINI, M. P. Análise documentária de fotografias: um referencial de leitura de imagens fotográficas para fins documentários. São Paulo, 2002. Tese (Doutorado) - Escola de Comunicações e Artes, USP.

MEYER, P. Catálogo de Selos do Brasil: 2015. São Paulo: RHM, 2015.

OLSON, H. A.; BOLL, J. J. Subject analysis in online catalogs. 2. ed. Englewood, CO: Libraries Unlimited, 2001.

PENEREIRO, J. C.; CABRINI, F. P. H. A visibilidade dos esportes e jogos por meio da filatelia brasileira. Rev. Bras. Ciênc. Esporte, Porto Alegre, v. 35, n. 4, p. 865-881, 2013.

PIETROFORTE, A. V. Semiótica visual: os percursos do olhar. São Paulo: Contexto, 2004.

SALCEDO, D. A. A ciência nos selos postais comemorativos brasileiros: 1900-2000. Recife: EDUFPE, 2010.

SMIRAGLIA, R. P. The progress of theory in knowledge organization. Library Trends, Champaign, v. 50, n.3.p. 330-349, 2002.

SOARES, M. S. B.; MARTIN, M. T.; FRANCELIN, M. M. Pluralismo lógico e epistemografia interativa como ferramentas desclassificadoras do conhecimento. Rev. digit. bibliotecon. cienc. inf., Campinas, v.11, n.1, p. 55-71, jan./abr. 2013

SOUSA, L. M. A. E.; FUJITA, M. S. L.; GRACIOSO, L. S. (Orgs.). A Imagem em Ciência da informação: reflexões teóricas, experiências práticas. Marília: Cultura acadêmica, 2014.

SVENONIUS, E. The intellectual foundations of information organization. Cambridge: The MIT Press, c2000. 255p. 